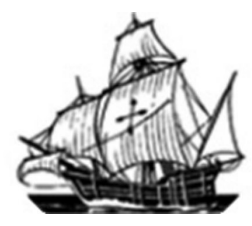

Nau Literária: crítica e teoria de literaturas • seer.ufrgs.br/NauLiteraria

ISSN 1981-4526・PPG-LET-UFRGS • Porto Alegre • vol. 09, n. 01・ jan/jun 2013

Dossiê: Voz e Interculturalidade

\title{
Vozes negras no candomblé baiano: Quando a raça importa e quando a raça não importa
}

\author{
Ari Lima ${ }^{1}$ \\ Nana Luanda M. Alves ${ }^{2}$
}

\begin{abstract}
RESUMO
Desde o final do século XIX, as religiões de orientação africana são seguramente um dos temas mais estudados no que diz respeito à problematização da presença africana e descendente no Brasil. Estas religiões têm agregado majoritariamente negros, mas também mestiços e brancos. Têm se constituído como uma reserva de memória, gestos, falas, relações e laços sociais de orientação africana, mas também de memória, gestos, falas, relações e laços sociais gerados durante a colonização, a escravidão e o pós-escravidão no Brasil. A hipótese deste trabalho - proposto ao Eixo de discussão: Vozes luso-africanas e negras, do III Seminário Brasileiro de Poéticas Orais -, é que um aspecto fundamental que também tem constituído o candomblé é a experiência da raça, do racismo e das desigualdades raciais que se manifesta ou é silenciada, em particular, através das vozes e das performances que lhe dizem respeito nos contextos desta religião. $\mathrm{O}$ trabalho é um resultado parcial de um projeto de pesquisa que propõe historicizar e mapear a prática religiosa de orientação africana em Alagoinhas, cidade localizada a $117 \mathrm{Km}$, da capital baiana, Salvador. Do ponto de vista teórico e conceitual, toma-se "raça" como constructo social que configura relações, racismo e desigualdades raciais orientadas por uma ideia do "negro". Logo, a vigência da raça é histórica, social, política e cultural, tanto quanto transversalizada por questões de gênero, sexualidade, origem territorial e interceptada por um continuum de cor e fenotipia. A pesquisa vem sendo realizada através de revisão bibliográfica sobre a temática das religiões de orientação africana, pesquisa em arquivos públicos e/ou privados, coleta de depoimentos e observação participante em espaços de prática religiosa de orientação africana em Alagoinhas. Neste caso, são consideradas dimensões de intersubjetividade, relações de poder dentro e fora do universo do candomblé e a complexidade da representação alheia através da enunciação e transcrição da voz. Também se busca menos a continuidade ou ruptura histórica através de detalhes documentados e mais a possibilidade de se inferir concepções básicas e estruturas simbólicas entre o passado e o presente. Do mesmo modo, de um ponto de vista

\footnotetext{
${ }^{1}$ Dr. em Antropologia Social pela UnB. Prof. Titular da Universidade do Estado da Bahia (UNEB). Professor Permanente do Programa de Pós-Graduação em Crítica Cultural da UNEB. Membro do GT de Literatura Oral e Popular da ANPOLL. E-mail: arilima.2004@uol.com.br

${ }^{2}$ Graduanda do curso de Licenciatura em História do Depto. de Educação/Campus II da Universidade do Estado da Bahia (UNEB). Pesquisadora de Iniciação Científica no Projeto "Quando a raça importa e quando a raça não importa nas religiões de orientação africana em Alagoinhas".
} 
analítico, esta pesquisa em vez de trabalhar com a noção de "matriz africana", que remete a um polemizado ideal de pureza e a uma ideia vaga de todo o continente africano, adota a noção de religião de "orientação africana" que aponta, porém não congela a referência à África.

Palavras-chave: Raça; Voz negra; História; Candomblé.

\begin{abstract}
Speeches of black in Baiano Candomble: when the race is important and when the race does not matter
\end{abstract}

Since the end of the 19th Century the religions of African orientation are certainly one of the most studied themes regarding to the problematization of African presence and black descendant in Brazil. These religions have aggregated mostly not only black people, but also mestizos and whites. They have constituted themselves not only as memory reservation, gestures, speeches, relationships and social ties of African orientation, but also memory, gestures, vocalizations, relationships and social ties generated along the colonization, slavery and the post-slavery in Brazil. The hypothesis of this study proposed to be discussed in Vozes luso-africanas e negras at III Seminário Brasileiro de Poéticas Orais is the fundamental aspect that has also been the Candomble (African religion in Brazil) which is, in turn, the experience of both race, racism and racial inequalities that manifests itself or is silenced particularly through the speeches and performances concerned to it in the contexts of this religion. This work is a partial result of a research project that proposes historicizing and mapping the religious practice of African orientation in Alagoinhas (a city in Bahia) far 72 miles away from Salvador (the capital of Bahia). From the theoretical and conceptual point of view, "race" is considered as a social construct that arranges relationships, racism and racial inequality guided by an idea of "black". Therefore, the continuity of the race is historical, social, political and cultural, as far as crossed by issues of gender, sexuality, territorial origin and intercepted by a continuum of color and phenotypes. This research has been conducted at a literature review based on the issues of religions of African guidance, in public file and/or private collection of witness as well as in participant observation at spaces of religious practice of African guidance in Alagoinhas. In this case, all these methods are considered dimensions of intersubjectivity, struggle relationship within and outside of the universe of Candomble and the representation of other by enunciation and transcription of speech. It was emphasized less the continuity or historical breaking through documented detail and more the possibility of inferring basic concepts and symbolic structures between the past and the present. In the same way, from an analytical point of view, instead of working with the concept of "African matrix", which refers to a polemic ideal of purity and a vague idea of the entire African continent, this research adopts the religious notion of "African guidance" that suggests but not freezes the reference to Africa.

Keywords: Race; Speeches of black; History; Candomble. 
Esta comunicação pretende apresentar e discutir dados parciais do projeto de pesquisa "Quando a raça importa e quando a raça não importa nas religiões de orientação africana na cidade de Alagoinhas“, situada a $117 \mathrm{Km}$ de Salvador, capital baiana. De fato, pretendemos menos realizar um estudo sobre a dimensão sagrada desta religião e mais entender e problematizar o dinamismo das relações e desigualdade raciais em Alagoinhas tomando como referência o contexto da prática de religião de orientação africana. A pesquisa tem sido realizada através de trabalho etnográfico, o que implica em observação de situações e relações cotidianas relacionadas a contextos e sujeitos específicos que compõem o universo do candomblé na cidade de Alagoinhas. Neste caso, são consideradas dimensões de intersubjetividade, relações de poder dentro e fora do universo do candomblé e a complexidade da representação alheia, em particular de candomblecistas, no texto etnográfico (SILVA, 2000). Além disso, na medida em que pretendemos historiografar a prática do candomblé em Alagoinhas, esta pesquisa deverá recorrer à transcrição e análise de prováveis documentos que existam sobre esta prática. Neste sentido, seguirá a indicação metodológica de "leitura para trás". Ou seja, se buscará menos a continuidade ou ruptura histórica através de detalhes documentados e mais a possibilidade de se inferir concepções básicas e estruturas simbólicas entre o passado e o presente (REIS, 1988).

Além disso, associada à provável documentação, a construção desta história do candomblé em Alagoinhas se fundamentará também na metodologia da história oral, englobando confessadamente a experiência subjetiva dos sujeitos e o modo enviesado em que a memória do candomblé em Alagoinhas tem se firmado (CRUIKSHANK, 1996). Do mesmo modo, de um ponto de vista analítico, esta pesquisa em vez de trabalhar com a noção de "matriz africana", que remete a um ideal de pureza polemizado pelos praticantes e pela literatura específica, assim como remete a uma ideia vaga de todo o continente africano, adotará a noção de religião de "orientação africana". Enfim, se recorrerá a um bibliografia especializada, a prováveis documentos públicos ou privados guardados em "arquivos mortos" e à memória de arquivos vivos que são os praticantes do candomblé. 
No que diz respeito à constituição de um campo de estudos e debate sobre as relações raciais no Brasil, a UNESCO teve um papel fundamental. Há poucos mais de 60 anos, a UNESCO patrocinou, em várias regiões brasileiras, estudos que pretendiam identificar aspectos econômicos, políticos, culturais e psicológicos influentes nas relações raciais (WAGLEY, 1963). Em tais estudos destacou-se, primeiro, a realização de observação etnográfica e levantamento de dados quantitativos em comunidades rurais; segundo, a relativização do preconceito e discriminação raciais a partir de marcas fenotípicas, que combinadas num mesmo indivíduo, em diferentes situações e contextos, o enegreciam ou o embranqueciam e terceiro as possibilidades surpreendentes de mobilidade social de negros, sem que o quadro de desigualdade racial e representação das raças fosse, de modo significativo, alterado. Pela qualidade intrínseca, mas também por sua relevância social, política e acadêmica, tais estudos se tornaram paradigmáticos nas ciências sociais brasileiras assim como projetaram os pesquisadores envolvidos e o Brasil nos debates internacionais sobre "raça" e "etnicidade". Enfim, o Projeto UNESCO

(...) não apenas gerou um amplo e diversificado quadro das relações raciais no Brasil, mas também contribuiu para o surgimento de novas leituras acerca da sociedade brasileira em contexto de acelerado processo de modernização capitalista. De uma outra perspectiva, o Projeto UNESCO veio a possibilitar a análise das trajetórias sociais e intelectuais dos pesquisadores envolvidos, das redes internacionais de cientistas, dos conteúdos teórico-metodológicos que informaram as pesquisas e do estado da arte de determinadas disciplinas, especialmente a Antropologia e a Sociologia. Ou seja, o ciclo de investigações chancelado pela instituição intergovernamental ofereceu uma oportunidade singular para $o$ desenvolvimento das ciências sociais no Brasil dos anos 50 (MAIO, 1999, p. 141).

Entres os pesquisadores brasileiros que participaram do Projeto UNESCO, o sociólogo baiano, radicado no Rio de Janeiro, Luiz de Aguiar Costa Pinto, desempenhou um papel destacado no que diz respeito à formulação daquela intervenção. Foi Costa Pinto, aliás, o responsável pela inclusão do Rio de Janeiro no roteiro de pesquisa, certo de que era importante refletir sobre a situação racial brasileira fazendo contrapor a pesquisa numa região tradicional, a Bahia, à pesquisa numa região em franco processo de industrialização (MAIO, 1998).

Foi fundamentalmente justa e fecunda, portanto, a resolução do Prof. (Alfred) Métraux (então representante do Departamento de Ciências Sociais da UNESCO) de não concentrar o estudo na Bahia. Do ponto de vista metodológico, ela foi de 
decisiva importância, pois ensejou a possibilidade de ser feito, pela primeira vez neste País, o estudo sociológico do negro nas áreas metropolitanas do Rio de Janeiro e São Paulo. (...) Partimos da verificação de que os estudos sobre o negro no Brasil quase que se limitaram, até hoje, a encarar o negro como um "espetáculo" - para usar a feliz expressão do escritor Sérgio Buarque de Holanda - no qual o centro do interesse estava localizado na assimilação do africano ao Novo Mundo, ou, mais particularmente, nos produtos desses processos sobre diversos setores da vida brasileira: religião, língua, culinária, vestuário, música. O negro brasileiro, ou melhor, o brasileiro negro e o processo de sua integração nos quadros da sociedade brasileira - da condição de escravo à de proletário e da condição de proletário a de negro de classe média -, jamais despertaram o interesse sério dos estudiosos do negro no Brasil, porque um arraigado estereótipo os convencera de que nada havia a estudar em relação ao negro igual a nós, ao negro não-africano, não-analfabeto, nãoescravo, não-trabalhador-rural, não separado do branco pela distância imensa que separa o vértice da base de uma pirâmide social rigidamente estratificada. O que o negro tinha de diferente de nós era o que se oferecia ao estudo: suas matrizes africanas, o drama de sua vinda para o Novo Mundo, sua condição de escravo, o estoque de influência que ele trouxe para cá e despejou fartamente na argamassa com que a história cimentou o chão e as vigas mestras da civilização brasileira (PINTO, 1998, p. 56; 57-58).

Deste modo, Costa Pinto chegou a contrariar as conclusões de observadores nacionais e estrangeiros, ao defender que, no caso do Brasil, também existia problema racial; que o problema racial no Brasil se manifestava de acordo com uma ideologia racial formulada ao longo de quase 400 anos do regime escravista; que casta e classe não são fenômenos diferentes, dois mundos ou pólos opostos, plenamente substituído um pelo outro. Ao contrário disso, são dois momentos reversíveis de uma sociedade em mudança que, informada por uma ideologia racial, pretende segregar os negros em novas castas e manter o branco em posição de privilégio racial e de poder. Para Costa Pinto, a pobreza científica dos conceitos utilizados e a fixação dos pesquisadores nos casos dos Estados Unidos, África do Sul ou Alemanha os impediam de compreender os mecanismos da discriminação e preconceito racial no Brasil num contexto histórico de desenvolvimento e mudança. Através da análise dos dados estatísticos que coletou sobre a situação do negro no Rio de Janeiro, então Distrito Federal, Costa Pinto concluiu que havia mobilidade social, entretanto homens e mulheres negros, exescravos e cidadãos de direito, tiveram sua integração à sociedade de classes determinada pela condição racial, ou seja, como negros.

Por outro lado, quando se lê a introdução e conclusão de trabalhos emblemáticos encomendados pelo projeto UNESCO, tais como Race and class in rural Brazil, organizado pelo pesquisador norte-americano Charles Wagley (1963), ou As elites de cor numa cidade brasileira, do pesquisador baiano Thales de Azevedo (1996), torna-se evidente o engajamento destes autores com uma certa política racial e com um programa antirracista bem definido, 
assumido pela UNESCO. "Tratava-se de demonstrar a possibilidade empírica de convivência de raças e etnias diversas, com o mínimo de tensão e conflito raciais" (GUIMARÃES, 1999, p. 130) e o Brasil como uma lição de democracia racial.

Charles Wagley (1963) acreditava que se havia problema racial no Brasil, tal problema não teria a configuração apresentada em outros países. No caso do Brasil, destacava o fato de que o povo brasileiro, do ponto de vista racial, era o resultado de três estoques raciais - a saber, o branco, o negro e o índio -, em variados graus de miscigenação. Observava e enfatizava a paz das relações raciais, assim como o fato de que, se por um lado, a fenotipia branca era decididamente preferida, por outro lado, a miscigenação estaria formando um povo brasileiro. Por conseguinte, concluiu que a classe e não a raça era o principal elemento de alinhamento social. A raça, na verdade, funcionava como um critério de sinalização da classe social dos indivíduos.

As elites de cor projetou seu autor e a Bahia internacionalmente assim como legitimou a autoridade acadêmica de Thales de Azevedo em âmbito nacional. Através da anotação e definição de categorias nativas de cor - branco, preto, mulato, pardo, moreno e caboclo -, Thales de Azevedo explicitou os imbricamentos entre classe, cor e status. Ao enfatizar estas categorias, evidenciou um "gosto étnico e racial" (SANSONE, 1999) nativo, manifestado sempre de forma ambígua, relacional, num contexto racializado onde ainda era constrangedor falar sobre discriminação racial e preconceito. Logo, em Thales de Azevedo, é o negro protegido, escolarizado, economicamente privilegiado, mas vigiado e embranquecido que se insere ou é inserido no mundo branco (LIMA, 2001).

Portanto, a discussão deste autor em torno da integração social das "pessoas de cor" e da inexistência de conflito racial, aparece contaminada pela ambiguidade da fala de seus interlocutores. Em As elites de cor, ao mesmo tempo que se tem uma promoção de um modelo de acomodação das raças e conflitos raciais, encontram-se originalmente sutis fontes estruturais de conflitos raciais que o autor não analisou. Ou seja, por Thales de Azevedo, as relações interpessoais legitimavam a idéia da harmonia e do mínimo de tensões raciais e ratificavam as posições hierárquicas e desiguais entre brancos e negros. Mas, por outro lado, sugeriam a constante suspeita e ameaça de que o negro assimilado por seu status adquirido pudesse reviver seus defeitos de temperamento, posturas corporais, caráter ou mentalidade racial desequilibrada (LIMA, 2001, p. 300).

Passados um pouco mais de 60 anos, após a execução do Projeto UNESCO, 
mudaram as noções de cor e raça, a percepção das desigualdades raciais no Brasil, inclusive por parte do Estado, verificou-se o argumento de Costa Pinto (1998) de que, se de um ponto de vista antropológico culturalista, o Brasil "não teria relações raciais", de um ponto de vista sociológico, as estatísticas dizem o contrário, como já provou em estudo seminal Carlos Hasenbalg (1979). Além disso, constituído o campo das relações raciais, ainda que de modo incipiente, vários programas de pós-graduação no Brasil vêm incorporando o tema das relações raciais em perspectivas locais e comparadas inovadoras. Entretanto, algo surpreendente neste campo é que normalmente o contexto religioso afro-brasileiro não motivou estudos e debates sobre relações raciais, sobre a percepção da raça e do racismo (v. AMARAL e SILVA, 1993; ORO, 1996 ). É bom lembrar, inclusive, que as pesquisas sobre as religiões afro-brasileiras se anteciparam em relação ao estudos sobre a raça propriamente dita e o pioneiro estudioso sobre estas religiões, Raimundo Nina Rodrigues (1862-1906), buscou através do estudo e observação das mesmas bem definir e descrever o negro e sua condição racial.

Portanto, desde o final do século XIX que as religiões de orientação africana são seguramente um dos temas mais estudados no que diz respeito à problematização da presença africana e descendente no Brasil. Embora estas religiões tenham se constituído e permanecido ao longo da história através do empenho de africanos e descendentes que neste contexto reconstituíram laços de parentesco, assim como rituais e mitos de deuses originalmente cultuados em África, estas religiões, como tais, foram determinadas historicamente, social e culturalmente pelo modelo de colonização portuguesa, pelo longo período de escravidão negra e permanente hegemonia branca. Ou seja, são religiões que remetem à África, mas que não puderam prescindir da realidade histórica, social e cultural onde se encontravam seus fundadores. Logo, estas religiões têm agregado majoritariamente negros, mas também mestiços e brancos. Têm se constituído como uma reserva de memória, de relações e laços sociais de orientação africana, mas também de aspectos gerados durante a colonização, a escravidão e o pós-escravidão. Nossa hipótese é que um dos aspectos fundamentais destas religiões é a experiência da raça, do racismo e das desigualdades raciais.

Desta forma, pretendemos alargar a compreensão acadêmica-científica do significado da experiência religiosa para o negro, mas também o que sejam a raça, as relações raciais e o racismo onde, a princípio, não deveriam estar ou parecem não estar. A propósito, compreendemos "raça" como constructo social e a necessidade de sua retomada de um ponto 
de vista sociológico (GUIMARÃES, 1999), de modo que se possa corrigir os equívocos das interpretações do passado que, primeiro, ratificaram uma noção biológica da raça, depois, substituíram o conceito de "raça" pela "cor" ou pela utopia da miscigenação democrática."Raça", portanto, é um constructo social que configura relações raciais orientadas por uma ideia do "negro", cuja vigência é histórica, social, política e cultural. Também é transversalizada por questões de gênero, sexualidade, origem territorial e interceptada por um continuum de cor e fenotipia.

A execução desta pesquisa se iniciou no segundo semestre do ano de 2012. Entretanto, só pôde cumprir apenas parcialmente o que se previu em sua primeira versão. Isto se deu devido à grande dificuldade em ultrapassar barreiras comuns para entrada e construção de confiança num campo de pesquisa muito delicado (SILVA, 2000). Deste modo, a partir de então, este subprojeto deve mapear com mais detalhes e construir uma história do candomblé em Alagoinhas e avançar na problematização da raça, das relações raciais e do racismo no âmbito de dois terreiros escolhidos. Na primeira fase desta pesquisa demos ênfase maior a revisitação dos estudos clássicos (BASTIDE, 1985; BASTIDE, 2001; CARNEIRO, 2008; LANDES, 1967; LIMA, 2003; RAMOS, 1988; RODRIGUES, 1988; RODRIGUES, 2005; PIERSON, 1967) referentes ao desenvolvimento das relações raciais brasileiras e às práticas religiosas de orientação africana, tentando estabelecer relações com a prática dessas religiões em Alagoinhas. A partir da revisitação desses estudos foi possível compreender o processo histórico de construção da nossa sociedade e perceber o lugar que a raça teve nesse processo. Os estudos realizados sobre as religiões de orientação africana nos informam que, nos tempos da Colônia e também posteriormente, estas religiões passaram a ser entendidas como um fator de ajustamento do indivíduo à sociedade. No seio de uma sociedade de estrutura escravista, o negro não podia se defender materialmente contra um regime onde todos os direitos pertenciam aos brancos e refugiou-se nos valores místicos. Assim, a religião desempenhou um papel nesta resistência contra o branco que foi, portanto, uma resistência religiosa e social. Foi ela, também, o único centro de integração no momento em que a abolição destruiu os raros laços de solidariedade existentes no Brasil. Enquanto a abolição desagregou a comunidade negra, o candomblé foi o refúgio e o apoio para esta população.

Foi a partir dessas considerações que partimos para a análise das estruturas religiosas do candomblé em Alagoinhas e a maneira como se perpetuam ou talvez se dissolvem as 
relações raciais nesses espaços. As primeiras entrevistas foram feitas com chefes de terreiros, respeitando a hierarquia que define toda a vida religiosa e social no candomblé. No entanto, o contato primeiro com os chefes dificultou, de certa forma, o contato com os demais membros das casas. Quando perguntamos sobre os filhos da casa, os pais e mães de santo disseram sempre que a maioria dos filhos reside ou são oriundos de outros lugares, principalmente da capital (Salvador). Assim, partimos para a entrevista de cerca de 10 adeptos que não estão vinculados diretamente aos terreiros visitados. Os entrevistados são de faixa etária diversa, assim como se encontram em posições sociais diferentes dentro e fora da religião. Todos, de certa maneira, conheceram a religião através da herança familiar e, alguns, nela permaneceram devido a questões de saúde. Todos os entrevistados perpetuam o discurso da não existência de tensões raciais no âmbito religioso. No entanto, essas tensões acabam por ser reveladas quando questionamos a forma de acesso e permanência de brancos e negros na religião. Como colocou um dos entrevistados, "se você tem dinheiro, tudo fica mais fácil. Sem dinheiro você consegue, mas demora um bom tempo". Se lembrarmos que historicamente a parcela branca de nossa população sempre foi, e ainda é, mais favorecida economicamente que a parcela negra, essa afirmação pode nos indicar que o acesso dos brancos e seu status dentro do candomblé acaba sendo facilitado pela utilização do dinheiro como recurso, situação equivalente, aliás, a outros contextos estudados (v. AMARAL e SILVA, 1993; ORO, 1996).

Como coloca Vivaldo da Costa da Lima (2003), o candomblé reconhece o praticante situado num grupo socialmente reconhecido e aceito e lhe transferee status e segurança. Nos casos estudados até então o fator econômico e o status que ele possui fora do círculo religioso determina qual o tratamento que ele terá dentro da religião. Do mesmo modo, o lugar ocupado pelos entrevistados na estrutura social e econômica mais ampla influencia diretamente na relação que estabelecem com o candomblé e na valorização atribuída à cultura negra e à herança africana. Entre todos os entrevistados, apenas um se definiu como negro. Os demais, apesar de apontarem a herança negra, se colocaram como mestiços. De fato, observamos, entre os entrevistados, que o lugar social e econômico que ocupam, bem como o acesso a cultura e ao conhecimento, influenciaram a construção de suas próprias identidades raciais. Os entrevistados que demonstraram uma percepção do candomblé como meio de valorização e resistência da cultura negra foram exatamente aqueles com uma melhor condição econômica e que tiveram acesso maior ao conhecimento e aos estudos. Uma outra constatação inicial é 
que, cada dia mais, o candomblé está iniciando pessoas de classes, raças diversas e mesmo estrangeiros, sem qualquer compromisso étnico ou cultural com os padrões dominantes nos candomblés ou com o que tradicionalmente tem sido observado. A chamada "religião de negros" parece está se tornando uma "religião de todos". No entanto, mesmo sob esse discurso, é possível perceber, senão uma tensão ao menos uma diferenciação racial camuflada pela diferenciação de classe.

Na pesquisa de campo realizada nos terreiros de candomblé na cidade de Alagoinhas, algumas questões se delinearam e conduziram à elaboração de divergências em relação ao observado e narrado pelos autores que tratam das religiões de orientação africana. No passado mais remoto, a religião afro-brasileira desempenhou um papel de resistência contra o branco, sendo o único centro de integração entre os negros. Hoje essa configuração já não pode ser observada de forma tão geral. A ideia do candomblé como forma de resistência cultural, através da qual o negro mantém sua identidade própria e vai de encontro à cultura branca dominante não esteve presente nos discursos dos adeptos entrevistados. Isso nos obriga a refletir sobre a maneira como se constrói a identidade negra nos dias atuais e até que ponto a prática religiosa do candomblé pode ser a ela associada.

Sabe-se que no Novo Mundo, os negros criaram de forma ativa uma cultura e uma “África” próprias (WINTZ e PRICE, 2003). Suas novas culturas (ou novos padrões culturais) tinham de significar algo para eles mesmos, bem como para os brancos. Assim, reformulando as tradições africanas, o candomblé se estruturou sob a forma de famílias de santo que reinventaram uma "comunidade negra" (LIMA, 2003). Mesmo com muitas modificações, ainda podemos encontrar alguns terreiros que mantém, ou aparentam manter, essa ideia de “comunidade negra". É o caso de uma das casas visitadas em Alagoinhas, onde se mantém, além do próprio terreiro, um ponto de cultura com vivência comunitária. No entanto, essa casa constitui uma exceção. O que se percebe é que a ideia de comunidade negra é muito mais utilizada por ativistas e intelectuais negros, por pessoas com um nível maior de instrução (no caso específico dos entrevistados em Alagoinhas).

Os adeptos do candomblé entrevistados em Alagoinhas, em sua maioria, perpetuam o discurso da não existência de tensões raciais no âmbito religioso. Mostram sempre uma religião aberta a todos, mas, mesmo que de forma sutil, algumas diferenciações são percebidas quando tratamos das questões raciais. Outro aspecto importante é que o argumento sugerido pelos diversos autores consultados e já citados aparece também nas falas dos 
entrevistados. Este argumento aponta para a crença de que a adesão ao culto de orientação africana faz com que o adepto se torne também "africano", assim como associa "África" a "negro", fazendo com que "africano" e "negro" sejam entendidos como sinônimos. Deste modo, o candomblé, tido como símbolo da cultura negra, poderia, além de africanizar, também enegrecer. Isto nos parece importante, na medida em que indica posicionamentos sobre as questões de raça e cor vivenciadas na prática do candomblé.

A propósito disso, Nina Rodrigues $(1988 ; 2005)$ afirma que o candomblé seria produto da natureza biológica do negro. Para ele, raça e cultura estariam intimamente ligadas, sendo a última transmitida geneticamente. Assim, mesmo que membros das "raças superiores" pudessem "se tornar negros" em suas práticas e costumes, devido às questões biológicas, o negro é que, de forma plena, traria a propensão a desenvolver as expressões da crença na magia e na feitiçaria do candoblé. No caso dos depoimentos dos adeptos entrevistados essa visão aparece de forma sutil, a vinculação da crença à biologia é ambígua e camuflada principalmente sob o discurso que considera o candomblé como uma "religião de todos". Ou seja, as falas dos nossos entrevistados tendem a afirmar que a construção de uma suposta identidade racial negra está vinculada à própria iniciação e participação no candomblé, porque o candomblé seria uma religião negra, com origens e raízes negras, porém o branco pode tornar-se negro através da iniciação, do transe e da prática religiosa.

Enfim, acreditamos que fazer uma análise dos dilemas e dificuldades no âmbito das experiências raciais e religiosas concretas, vividas no candomblé, nos fornece elementos para tentar entender e enfrentar os dilemas que a questão racial desperta nos brasileiros. Mesmo porque, quando nos dispomos a trabalhar com a questão da raça é necessário perceber que, para além de conceitos, estamos lidando com algo bastante subjetivo que envolve a constituição de identidades por si mesmo e pelo outro; identidades individuais e coletivas afirmadas ao mesmo tempo que negadas no modo como se enuncia voz, corpo e consciência de si. Além disso, ao se fazer um estudo que enfatiza as relações raciais no candomblé, abrimos um leque de conexões com temas como identidade negra, cultura brasileira e tradições africanas repletas de muitas nuances.

O que é necessário observar é que a religião pode ser entendida como prática que possibilita compreender a multiplicidade da experiência e os processos de transformação histórica e social da realidade dos negros. Logo, através do estudo das religiões podemos entender melhor a relação entre as determinações materiais e os elementos subjetivos no 
processo de construção das identidades raciais e de que forma os sujeitos articulam a experiência e a cultura para agir sobre uma situação determinada. Assim é importante colocar em análise o papel da cultura como mediadora das relações e estruturas para perceber que os sujeitos aqui observados não são simples presas de forças externas e determinantes, tendo desempenhado um papel ativo e essencial na criação de sua própria história e na definição de sua própria identidade cultural e social. 


\section{REFERÊNCIAS BIBLIOGRÁFICAS}

AMARAL, Rita de Cássia; SILVA, Vagner Gonçalves da. A cor do axé: brancos e negros no candomblé de São Paulo. Estudos afro-asiáticos, nº 25, dezembro de 1993.

AZEVEDO, Thales. As elites de cor numa cidade brasileira. Um estudo de Ascensão Social \& Classes Sociais e Grupos de Prestígio. Salvador: EDUFBA/EGBA, 1996.

BASTIDE, Roger. As Religiões Africanas no Brasil. São Paulo, Livraria Pioneira Editora. 1985.

BASTIDE, Roger. O candomblé da Bahia: rito nagô. São Paulo: Companhia das Letras, 2001. CARNEIRO, Edison. Candomblés da Bahia. São Paulo: Editora WMF Martins Fontes, 2008.

CRUIKSHANK, Julie. Tradição oral e história oral: revendo algumas questões. In: FERREIRA, Marieta de Moraes e AMADO, Janaína (orgs.). Usos e abusos da história oral. RJ: Editora da Fundação Getulio Vargas, 1996. p. 149-166.

GUIMARÃES, Antonio Sérgio Alfredo. Racismo e Anti-racismo no Brasil. São Paulo: Ed. 34, 1999.

HALL, Stuart. Identidade cultural na pós-modernidade. Rio de Janeiro: DP\&A, 1999.

HASENBALG, Carlos A. Discriminação e Desigualdades Raciais no Brasil. RJ, Edições Graal, 1979.

LANDES, Ruth. A Cidade das Mulheres. Rio de Janeiro: Civilização Brasileira, 1967.

LIMA, Vivaldo da Costa. A família de santo nos candomblés jejes-nagôs da Bahia: um estudo de relações intragrupais. Salvador: Corrupio, 2003.

MAIO, Marcos Chor. Costa Pinto e a crítica ao "negro como espetáculo". Apresentação. In: 
PINTO, Luiz Aguiar Costa. O negro no Rio de Janeiro: Relações de raça numa sociedade em mudança. 2. ed. Rio de Janeiro: Editora UFRJ, 1998. pp. 17-50.

. O Projeto UNESCO e a agenda das ciências sociais no Brasil dos anos 40 e 50. Revista Brasileira de Ciências Sociais , v. 14, no 41, São Paulo, Outubro de 1999. pp.141-158. ORO, Ari Pedro. As relações raciais nos terreiros do Rio Grande do Sul. Trabalho apresentado no GT 19 - Relações raciais e etnicidade - do XX Encontro Anual da ANPOCS, Caxambu, 22-26 de outubro de 1996. p.1-24.

PIERSON, Donald. Brancos e Pretos na Bahia. São Paulo:Companhia Editora Nacional, 1967.

PINTO, Luiz Aguiar Costa. O negro no Rio de Janeiro: Relações de raça numa sociedade em mudança. 2. ed. Rio de Janeiro: Editora UFRJ, 1998.

RAMOS, Arthur. O negro brasileiro. Etnografia religiosa e psicanálise. Recife: Fundação Joaquim Nabuco/ Editora Massangana, 1988.

REIS, João José. Magia Jeje na Bahia: a invasão do calundu de Pasto de cachoeira, 1785.

Revista Brasileira de História. São Paulo, v. 8, nº 16, mar. 88/ ago. 88. p. 57-81.

RODRIGUES, Raimundo Nina. Os africanos no Brasil. São Paulo/Brasília: Ed. Nacional/ ed. Universidade de Brasília, 1988.

RODRIGUES, Raimundo Nina. O animismo fetichista dos negros baianos. Salvador, 2005. P555, (Coleção A/C \Brasil, 2).

SANSONE, Livio. O Olhar Forasteiro: Seduções e ambigüidades das relações raciais no Brasil. In: BACELAR, Jeferson Bacelar e CAROSO, Carlos. Brasil: um país de negros?. Rio de Janeiro/Salvador: Pallas/CEAO, 1999. pp.15-33.

WAGLEY, Charles. Race and class in rural Brazil. Paris: UNESCO, 1963. 
WINTZ, Sidney W. e PRICE, Richard. O nascimento da cultura afro-americana. Uma perspectiva antropológica. Rio de Janeiro: Pallas/ Universidade Cândido Mendes, 2003. 